\title{
Did the Healthcard program ensure access to medical care for the poor during Indonesia's economic crisis?
}

\author{
Menno Pradhan ${ }^{1}$, Fadia Saadah ${ }^{1}$ and Robert Sparrow ${ }^{2}$ \\ December 2002
}

\begin{abstract}
The Indonesian Healthcard program was implemented in response to the economic crisis, which hit Indonesia in 1998, in order to preserve access to health care services for the poor. The Healthcard provided the households with subsidised care at public health care providers, while the providers themselves received budgetary support to compensate for the extra demand. This papers looks at the impact of this program on outpatient care utilisation, and, in particular, endeavours to disentangle the direct effect of the allocation of Healthcards from the indirect effect of the transfer of funds to health care facilities. It finds that the program resulted in a net increase in utilisation for the poor beneficiaries. For non-poor beneficiaries the program resulted in a substitution from private to public providers only. However, the largest effect of the program seems to have come from a general increase in the quality of public services resulting from the budgetary support they received through this program.
\end{abstract}

The authors would like to thank Dominique van de Walle, Jan Willem Gunning and Maarten Lindeboom and seminar participants at the World Bank, 2001 IHEA and GDN conferences for useful comments. 1. World Bank. The views expressed in this paper reflect those of the authors and not necessarily those of the World Bank. 2. Vrije Universiteit Amsterdam. Correspondence to: Menno Pradhan, World Bank office Jakarta, Jakarta Stock Exchange Building Tower 2, 12th floor, Jl jenderal Sudirman Kav 52-53, Jakarta 12190 Indonesia, mpradhan@worldbank.org 


\section{Introduction}

Targeted prices subsidies for outpatient medical care are often advocated as a means to increase access to medical care for the poor under budgetary constraints. Empirical evidence from developing countries show high income elasticities for health care, and thus large inequalities between poor and rich, but rather low price elasticities that tend to be larger for the poor (Jimenez, 1995). Subsidised prices for the poor can thus be effective in increasing their demand. General price subsidies for medical care have high leakage rates in the sense that a large proportion of the subsidy ends up with the non-poor. Price subsidies that apply only to the poor can provide a cost-effective way of ensuring access for the poor within a tight budgetary environment.

This case study looks at a very particular kind of targeted price subsidy that was applied in Indonesia in response to the economic crisis, which hit the country in 1997. First, the price subsidy only applied to public service providers. Private sector health care providers were not included in the scheme. Second, there was a loose relationship between the utilisation of the Healthcard - which entitled the owner to the subsidy - and the compensation the healthcare providers received in return. Compensation was allocated to districts based on the estimated number of households eligible for a Healthcard and not based on actual utilisation of the Healthcard. The transfers were made directly to the public health care facilities.

This paper focuses on the effect of the Indonesian Healthcard program on demand for primary outpatient health care. The particular design allows us to investigate a number of interesting questions. First, since the Healthcard only entitled the user to free services at public providers we can investigate substitution effects between private and public providers. This is difficult in the models which estimate the demand for medical care based on variations in travel time and opportunity costs to the nearest provider (Gertler and van der Gaag 1990, Dow 1999). Opportunity costs do not vary by public or private provider and the same will often hold for travel time. For instance, doctors working at public providers in Indonesia also often maintain private practices making it impossible to use travel time variation to estimate 
substitution effects. Second, we can compare the effect of transfer to public sector providers with a price subsidy. We will argue that these transfers made to the public sector providers in effect resulted in an overall quality increase of the public sector. The price subsidy was only applicable to those who received a Healthcard. We make an attempt to disentangle the two effects. Finally, once the direct and indirect effects of the Healthcard program have been identified we plan to evaluate the distribution of the effect across consumption quintile and gender.

The study is based on data from the nation-wide Susenas household survey. The 1999 round of this survey contained a special module to measure the use of the Social Safety $\mathrm{Net}^{2}$ interventions, of which the Healthcard program was one component. It was fielded in January 1999. The Healthcard program started in September 1998. The results of this analysis thus reflect the experience of the first months of operation of the program. The survey sampled 205,747 households and had nation-wide coverage. It collected a wide range of socio-economic indicators along with a measure of consumption. In the area of health, the survey collected information on self-reported illness, utilisation of medical services, user fees and ownership and utilisation of the Healthcard.

Besides the micro data we also use administrative data concerning the 1998/1999 budget for the Social Safety Net program. This data includes the budget allocated to 293 districts (kabupaten) to implement the Healthcard program and to compensate the public health clinics (Puskesmas) and village midwifes (bidan di desa) for the expected extra demand for health services resulting from the Healthcard program. The largest share of this budget was directly transferred to public health care providers. The transfers were made in two to four phases, depending on the province, starting in the last quarter of 1998.

The organisation of the paper is as follows. In section 2 we describe the Healthcard program in more detail and investigate whether the implementation matched the design. We will present descriptive statistics on ownership and utilisation of the Healthcard and trends in the utilisation of medical services. Section 3 focuses on the

\footnotetext{
${ }^{2}$ SSN (2000) and Ananta and Siregar (1999) provide an overview of the SSN program.
} 
impact of the Healthcard on utilisation rates of medical services and section 4 concludes.

\section{Utilisation of medical services and the Healthcard program}

The economic crisis hit Indonesia in the fall of 1997. Poverty increased sharply, mostly as a result of sharp increases in the price of food. Suryahadi et al (1999) estimate an increase in the poverty head count ratio from 6.5 percent in October 1997 to 17.8 percent in January 1998. Observed trends in the utilisation of medical services over this period are presented in Figure 1. The data are based on a series of Susenas household surveys and present utilisation in the month of January of that year. The figure indicates a sharp decrease in the utilisation of modern health care from 1997 to 1998, mostly as a result of the drop in the utilisation of public sector providers. Saadah et al. (2000) attribute this trend to a decline in the quality of public sector providers. From 1998 to 1999 total utilisation of modern health care providers remained the same, but the share of the public sector increased. One possible explanation is the Healthcard program, which started during this period. We will investigate the empirical foundation of this hypothesis.

The design of the Healthcard program is as follows. Healthcards were distributed across districts based on the estimated number of poor. Healthcards were sent out to the local leaders at the district level starting August 1998. Along with the Healthcards they received guidelines on which criteria to use when distributing the Healthcard to households. The poverty measure that was used as criterion for both the allocation of block grants to facilities and households eligibility for Healthcards, was the so called "prosperity status" of the household. Under this definition a household is deemed in need when they have insufficient funds for any one of the following: (i) to worship according to faith, (ii) eat basic food twice a day, (iii) have different clothing for school/work and home, (iv) have a floor not made out of earth, or (v) have access to modern medical care for children or access to modern contraceptive methods. This information is collected by the national family planning board (BKKBN) on a census 
basis. The local leaders however maintained a lot of leverage at the local level to distribute Healthcards according to their own insights.

The Healthcard entitled the owner and family members to free services at public healthcare providers consisting of (1) outpatient and inpatient care, (2) contraceptives for women in child bearing age, (3) pre-natal care to (4) assistance at birth. Service providers were compensated for the additional workload by a lump sum transfer which was based on the number of Healthcards allocated to the district. In this paper we limit ourselves to the impact of the Healthcard program on outpatient healthcare utilisation.

Table 1 provides descriptive statistics for Healthcard owners and others. Column 1 shows the statistics for households without a Healthcard, while column 3 shows the characteristics for households that did receive a Healthcard. The Healthcard program is of a substantial magnitude. 10.6 percent of Indonesian households report ownership of a Healthcard. It appears that Healthcard owners are poorer, have lower education, live more often in female headed households and work more often in agriculture compared to non-Healthcard owners.

Utilisation rates are provided in Table 2.15 percent of the Healthcard owners visit an outpatient provider during a period of 3 months, compared to 13 percent for the nonHealthcard owners. Healthcard owners tend to choose more often public providers. They do not, however, always use their Healthcard. 4 out of 11 percent of the Healthcard owners report not to use the Healthcard when seeking care at a public provided. Also we find some instances that a Healthcard is used while the household head reports not to own a Healthcard. Technically, these type of occurrences are possible because ownership is collected from the household head while utilisation is collected by individual. Qualitative research by Soelaksono et al. (1999) suggests several reasons why Healthcard owners did not always use their Healthcard for treatment. They find that in some public facilities, the time allocated to patients with a Healthcard was limited, and that in remote areas the lack of access to the nearest public facility was a possible deterrent to use the Healthcard. They also found strong indications that patients perceived the care received using a Healthcard to be of lower quality than services and medicines obtained when not using the Healthcard. Non- 
owners reporting using a Healthcard could occur if Healthcards are distributed at the clinic based on needs. In such instances the household head may not have been aware of that a family member received benefits under this program. Suggestive evidence in support of this explanation comes from the positive correlation we find between Healthcard ownership and self reported illness in the past month.

Ownership of Healthcards is distributed pro-poor ${ }^{3}$. Utilisation of Healthcards is also pro-poor but slightly less so. The concentration curves for ownership and utilisation are presented in Figure 2. Those who received benefits were on average wealthier than those who received the card. The poorest 20 percent of the population owns 35 percent of the Healthcards. Still there is considerably leakage. Considering that about 10 percent of the households received a Healthcard, perfect targeting would imply that all Healthcards were obtained by the poorest 10 percent of the population. About 39 percent of the Healthcards are owned by households from the wealthiest three quintiles.

\section{Impact of Healthcard Program on utilisation}

In this section we concentrate on the question: what would have been the utilisation of outpatient health services if the Healthcard program had not existed? Note that the question comprises two effects: the effect of the Healthcard program on the Healthcard owners and the effect of the program on the household that did not receive a Healthcard. The second effect cannot assumed to be zero as is usually assumed in an impact evaluation. There may have been a general increase in quality of services as a result of the additional transfers that were made to the public providers. We will analyse both effects. Our approach is to treat the two effects as two separate interventions. One is the distribution of Healthcards to those in need (the pure Healthcard program), the second is a general increase in budgetary support to public sector services. The maintained assumption is that the first intervention - the distribution of Healthcards - did not have any effect on the quality of the public

\footnotetext{
${ }^{3}$ Ranking of household based on per capita consumption is complicated by the fact that one third of the sample received a more detailed consumption questionnaire than the rest. Our approach has been to generate two separate rankings for each sample and average the results as suggested in Pradhan (2001).
} 
services. It accrues benefits only to those who actually own a Healthcard. The second intervention affects the whole population.

The impact of the first intervention - the distribution of Healthcards - can be analysed by forming a control group from the population that did not receive a Healthcard. Since both Healthcard and non-Healthcard owners benefited from thetransfer of funds to health care providers, this measures the differential effect of owning a Healthcard conditional on the transfer program. For the second intervention - the general increase in the budget of public health care providers - it is not possible to create a control group from the same sample as this intervention affected everyone. The impact of the total program is estimated using a dynamic approach exploiting the variation in compensation for the Healthcard program to public health clinics (Puskesmas and bidan di desa) across districts. We analyse the utilisation rates before the introduction of the Healthcard program - based on the 1998 Susenas - with the situation right after the introduction of the Healthcard program. The resulting impact estimate is a result of the two interventions acting simultaneously. The impact of the general increase in funding to public services is then obtained by subtracting the former estimate from the latter.

Somewhat more formally, the combined average impact of the two interventions can be written as the sum of the two impacts separately. Let $Y(h, q)$ denote the outcome as a function of the two interventions. Both $h$ and $q$ take on the value 0 or 1 and $h$ refers to the pure Healthcard program and $q$ refers to the general budget increase for public services intervention. Then, the average total effect of the program can be expressed as

$$
E[Y(1,1)]-E[Y(0,0)]=[E[Y(1,1)]-E[Y(0,1)]]+[E[Y(0,1)]-E[Y(0,0)]]
$$

The first term on the right hand side reflects the pure effect of the program conditional on the budget increase, while the second term indicates effect the budget increase. We will refer to the latter as the indirect effect of the JPS program. The impact of the pure Healthcard intervention is a weighted mean of the impact on the treated population 
(Healthcard owners) and non-treated population (others). If we assume the latter to be zero, then

$$
\begin{aligned}
& E[Y(1,1)]-E[Y(0,1)]= \\
& p E[Y(1,1) \mid s=1]+(1-p) E[Y(1,1) \mid s=0]-p E[Y(0,1) \mid s=1]-(1-p) E[Y(0,1) \mid s=0]= \\
& p[E[Y(1,1) \mid s=1]-E[Y(0,1) \mid s=1]]
\end{aligned}
$$

where $s=1$ if the household selects into the program (owns a Healthcard) and $p=$ $\operatorname{Pr}(s=1)$, the probability of selection into the program.

First, we concentrate on the estimation of the impact of the pure Healthcard intervention. For obvious reasons, a direct comparison between Healthcard owners and non-Healthcard owners after the introduction of the program does not yield a valid impact estimate. The expressions above are conditional upon selection and since selection was not random, we cannot presume that $E[Y(0,1) \mid s=1]=E[Y(0,1) \mid s=0]$.

The Healthcard was distributed to poor households, and even without a Healthcard their utilisation would have been different from the relatively well off non-Healthcard households. There are various approaches one can take to correct for this non-random placement of the program. Two frequently used methods are instrumental variables and propensity score matching. The first relies on finding an exogenous variable, which has an effect on the probability of obtaining a Healthcard, but has no direct effect on the probability of using a health service. Although one variable that satisfies these criteria is sufficient to obtain an unbiased estimate of the average treatment effect, the method has its weaknesses. In particular, the assumption whether the chosen instrumental variable has no direct effect on utilisation cannot be tested. The second approach aims at removing the differences between the control and treatment group by matching on observed characteristics. Here the researcher defines the matching variables. The main weakness of this method is that one cannot be sure that all bias - that is systematic differences between the control and treatment group which influences utilisation - has been removed during the match. 
In this paper we will use the propensity score matching approach. The reason for not using the instrumental variable approach is that we are not convinced that we are able to construct convincing instruments. We experimented with using variables that measure the perception of fairness of the distribution of Healthcards in the district. The village leave-out-mean, crossed with wealth variables, we thought may provide a valid instrument. Wealthy people, living in villages where the distribution was unfair, would have a higher probability of receiving a Healthcard. There is no reason to assume that the fairness of the distribution would have a direct effect on utilisation. After some experimenting, however, we decided to abandon this approach. The method appeared very sensitive to the choice of instruments that was used. Small changes in the specification led to large differences in the estimated impact, indicating a weakness of the instruments that were used.

Propensity score matching relies on matching on observables. Recent advances have greatly increased the popularity of this method. The likelihood that all bias between the control and treatment group is removed increases when more variables are used to match. On the other hand, the more variables are used, the more difficult it is to find a match. Rosenbaum and Rubin (1983) proved that if it is valid to match on all of the selected variables separately, it is equally valid to match on the propensity score only. The propensity score predicts the probability of obtaining treatment as a function of the observed matching variables. This greatly reduces the dimensionality of the problem. Instead of having to match on several variables, all we have to do now is to match on one variable, the propensity score.

The propensity score function can be estimated easily by running a logit model. The unit of analysis is the household, as Healthcards were distributed at this level. Households in the treatment group are matched to households in the potential control group. As a result, the sample size of the treatment and matched control group are different as the household sizes vary. 
We estimated the propensity score function separately for five main regions in Indonesia. ${ }^{4}$ In this way we restricted the match to households living in the same region. A household with a Healthcard living in Java could for instance, never be matched with a household without a Healthcard living in Sumatra. The reason for doing so is that we believe that there are unobserved characteristics which vary by region that influence the effect that other variables have on the probability of receiving a Healthcard. An alternative would have been to estimate a fully interacted model where each variable is interacted with the region dummies. This however would have created considerable computation problems. The Pseudo R squared for the regional models ranged from 0.12 to $0.26 .^{5}$

To capture the influence that district leaders exercised over the distribution of the Healthcards we included district fixed effects in each of the models. In addition to the district fixed effects, 84 variables were included in the matching function. These refer to housing characteristics (status of house occupied, type of roof, type of wall, type of floor, source drink water, drink water facilities, source of light, type of toilet facilities, type of feaces collector), household composition (by gender and age), household size, head of household (sex, education level, type of employment), sector of main source of household income, per capita consumption, IDT (poor village program) village classification, BKKBN prosperity variables ( household can worship according to respective faiths, can eat basic foods twice or more per day, owns different clothing for home/work/ school/travel, most floor space made of materials other than earth, a health facility/official is available of for modern medicine/KB method when a child is sick or a fertile couple wishes to use KB), cluster leave out mean of perception variables (questions referring to adherence to procedures for allocation Healthcards and appropriateness of recipients).

The second step is to match. Every household with a Healthcard was matched to a household without a Healthcard based on the estimated propensity scores. We tried to match as much as possible without replacement, that is, once a household from the potential control group was matched, we tried not to use it again for another match.

\footnotetext{
${ }^{4}$ The 5 regions we define are (i) Java and Bali, (ii) Sumatra, (iii) Sulawesi, (iv) Kalimantan and (v) Other Islands.

${ }^{5}$ The estimation results of the logit models are available on request from the authors.
} 
This approach however, yielded a shortage of possible matches for those households with a high propensity score (who have a high probability of being in the treatment group). We used the rule that when the match obtained without replacement had a propensity score that differed more than 0.02 from the propensity score of the household in the treatment group, we resorted to matching with replacement. If no match was found within a radius of 0.02 we did not match the household to a control. This way of constructing a control group boils down to a reweighing of the potential control group. Those households that are not matched receive a weight of zero, those who are matched once receive a weight of one, and those matched more than once receive a weight higher than one.

The quality of match is best illustrated using a graph. Figure 3 shows the propensity score of all households who have a Healthcard ranked from low to high. The other dots in the graph show the propensity scores of the matched households. The proximity of the two curves indicates that we were able to find a good match. The match is virtually perfect for households with a propensity score below 0.4. Above that level, the match is still close but distinguishable in the graph. The matched sample and sample of households which owns a Healthcard also is very similar on the basis of the individual observed characteristics which entered into the matching function. This is evident from Table 1, where column 2 and 3 present the descriptive statistics for the matched samples, and columns 4 and 5 show the difference in means of the covariates. The table shows that the two samples are well balanced across the observed characteristics.

Once the pairs are matched, the differential impact of ownership of a Healthcard can be estimated by comparing utilisation patterns of the treatment and matched control group $^{6}$. Comparing means yields the average impact of the pure Healthcard

\footnotetext{
${ }^{6}$ Note that the pure effect of the Healthcard program is conditional upon budget increase effect. The assumption is made that the matched pairs are balanced in terms of the latter effect. We argue that if the district dummies - which are included in the propensity score function - are balanced, then so is the budgetary support to public health care facilities at district level. We conducted various test on the matched samples to see whether the distribution of the two populations across districts varied systematically. No systematic differences were found. Beyond the district level we can not test this assumption. We will assume that at within districts the benefit of the budget transfer program (q) is homogenous.
} 
intervention on Healthcard owners. It can easily be obtained by estimating the regression

$$
Y_{i}=\delta+\beta H C_{i}+\varepsilon_{i}
$$

on the matched sample applying sample weights. $\beta$ is an unbiased estimate of the pure treatment effect for those who are selected into the program, $E[Y(1,1) \mid s=1]-E[Y(0,1) \mid s=1]$ in equation (2). The estimated average pure Healthcard effect, as defined in equation (2), is then $\hat{p} \hat{\beta}$, where $\hat{p}$ is the estimated probability of selection into the program $(\operatorname{Pr}(\mathrm{s}=1))$.

The overall impact of the Healthcard program is obtained by exploiting regional variation in the financial compensation for the Healthcard program to public health care providers. To measure this variation we use administrative data concerning the 1998/1999 budget that was allocated for transfers to public health facilities. The variation was substantial. For example, we found that the amount of compensation, weighted by the district population size, in Sulawesi is 38 percent higher than in Sumatra and 33 percent higher that in Java/Bali, but about half of what is allocated to the smaller islands (Table 3). We model the effect of the general increase in funding as a linear function of the budget allocation. For district $j$, in time period $t$, the utilisation of health services is written as

$$
\left[E\left[Y_{j t}(1,1)\right]=\alpha_{j}+\delta_{0} t+\sum_{i=2}^{5} \delta_{i} r_{i} t+\gamma \frac{J P S_{j}}{N_{j}}+\varepsilon_{j t}\right.
$$

where $J P S_{j}$ is the amount of compensation for public health clinics allocated to district $j, N_{j}$ denotes the district population size, and $t$ is a time variable, taking value $t=0$ to indicate the time period before the intervention (1998) and $t=1$ for the time period after the intervention (1999). The time variable has also been interacted with 5 region dummies, in order to allow for some flexibility in capturing the time effect. ${ }^{7}$ For the pre-intervention data $J P S_{j}$ equals zero for all districts. The non-random allocation of

\footnotetext{
${ }^{7}$ Java and Bali (region 1) are used as reference group.
} 
budget allocation is accounted for by incorporating a time invariant district fixed effect. To the extent that the allocation of compensation for the Healthcard program was determined on the basis of such, district specific time invariant, variables this takes account of the endogeneity problem. The fact that the budget allocation was determined on the past of historic poverty estimates and not on the basis of dynamic changes in poverty legitimises this approach. The model can be estimated by taking differences across regions over time

$$
E\left[Y_{j 1}(1,1)\right]-E\left[Y_{j 0}(0,0)\right]=\delta_{0} t+\sum_{i=2}^{5} \delta_{i} r_{i} t+\gamma \frac{J P S_{j}}{N_{j}}+\Delta \varepsilon_{j t}
$$

The average total effect is then obtained by

$$
\left[E\left[Y_{1}(1,1)\right]-E\left[Y_{1}(0,0)\right]\right]=\sum_{j=1}^{d}\left[\hat{\gamma} \frac{J P S_{j}}{N_{j}} \frac{N_{j}}{N}\right]=\hat{\gamma} \overline{J P S}
$$

where $\overline{J P S}$ is the average financial compensation for the Healthcard program per district across the country.

Now that we have an estimate of the average total effect and the average pure Healthcard effect we can calculate the average impact of the improvement in public services. Inserting (6) and the estimate of $\beta$ in (3) into (1) yields an expression for the impact of the general budget increase for public service providers

$$
[E[Y(0,1)]-E[Y(0,0)]]=\hat{y} \overline{J P S}-\hat{p} \hat{\beta}
$$

For the utilisation of outpatient services we will report both the pure Healthcard effect and the total effect based on the dynamic approach.

Table 4 reports the pure Healthcard effect on outpatient utilisation for Healthcard owners $(\hat{\beta} * 100)$ and the average pure effect $(\hat{p} \hat{\beta} * 100)$, using both the one month and a three months reference period (both based on the propensity score matched 
sample). The estimates are multiplied by 100 as to express the treatment effects in terms of percentage points. The last column of the table gives the estimates of $\hat{p}$, which is simply fraction of individuals that live in a household that owns a Healthcard for the relevant (sub-) population. The table also shows utilisation of outpatient services for the matched intervention and control groups, in terms of percentages. The results so far have been based on a three months reference period, which was used in the Social Safety Net module of the 1999 Susenas. However, the Core of the Susenas also collects utilisation using a one month reference period. This is collected each year and will be used in the dynamic analysis. Irrespective of the reference period, the results tell a clear story. Healthcard ownership resulted in a significant increase in the use of outpatient services. This increase was mostly due to an absolute increase in utilisation from the poorest three quintiles, while for the richer quintile we only observe a substitution effect from private to public health care providers. For all income groups Healthcard ownership resulted in an increase in the use of public sector services and a decrease in the use of private sector services. For the richest quintile the two effects cancelled out and resulted in no significant increase in overall utilisation. The Health card program affected utilisation amongst women more than it did amongst men. Both the overall increase in outpatient visits and the substitution effect from private to public were larger for women.

Table 5 presents the estimates of $\gamma$, as introduced in equation (5), and the estimates of the pure Healthcard effect $(\hat{\gamma} \overline{J P S} * 100)$, defined in equation (6). Again, the estimates have been multiplied by 100 to reflect the effects in terms of percentage points. $\overline{J P S}$ is a constant value 1.422 (see Table 3). The results indicate significant increases in the use of public sector services, while the program does not affect the use of private sector services. We do not find many significant results for utilisation by quintile, although there is a slight indication that the effect is smaller in higher quintiles. The overall effect on utilisation of public services by males and females is significant, but we do not find large differences as with the pure Healthcard effect. We find similar results for the overall effect on utilisation.

Having estimated both $\hat{\gamma} \overline{J P S}$ and $\hat{p} \hat{\beta}$ allows us to investigate what share of the increase in the use of public sector services is due to the indirect effect (as defined in 
equation (7)) and the pure Healthcard effect respectively. Combining the estimates in Table 5 with those referring to the one month reference period in Table 4 yields and estimate of the effect of the general budget increase. In terms of the reported results in these tables, the share of the indirect effect to the total effect is given by $1-((\hat{p} \hat{\beta} * 100) /(\hat{y} \overline{J P S} * 100))$. About 82 percent $(1-(0.106 \cdot 1.06) /(0.45 \cdot 1.422))$ of the overall increase in utilisation is a result of the indirect effect. In the public sector about two thirds of the total increase can be attributed to the indirect effect $(1-(0.106 \cdot 1.82) /(0.40 \cdot 1.422))$. This strong indirect effect, which could be attributed to an overall increase in the quality of public sector providers as a result of the extra budget support, seems to have been a main contributor to the increase in the use of public sector services.

So can the revival of the public sector utilisation be attributed to the Social Safety Net Program? It appears to be. The estimates reported in Table 5 can be used to estimate the utilisation if the Healthcard program had not existed. From (6) it shows that the impact on overall utilisation is the estimate of $\gamma$ times the average compensation to health $(\overline{J P S})$. The results indicate that Healthcard program increased outpatient contact rate by 0.64 percentage point and the contact rate at public facilities by 0.57 percentage point (Table 5). In Figure 1, where we reported the trends in health care utilisation by type of provider, we added the counterfactual of what would have been public and private sector utilisation in absence of the Healthcard program. From 1998 to 1999 the contact rate for public sector services increased from 5.0 to 5.3 percent, while the contact rate for modern health care providers remained stable at 10.5 percent. The estimates suggest that without the Healthcard program public sector utilisation would have dropped further to 4.7 percent, and the overall contact rate would have dropped to 9.9 percent.

\section{Conclusion}

This paper presented an analysis of operation and impact of the Healthcard program as it operated under the Social Safety Net program in its very first months. It shows that in many ways the program was a success. In other ways the program has achieved things which may not have been the objective at the outset. The Healthcard program 
has a weak link between the delivery of services to Healthcard owners and the financial compensation. Service providers were reimbursed using a lump sum transfer based on the number of Healthcard distributed to their area of influence. As a result, serving a Healthcard owner did not result in a direct financial reward to the service provider. This makes the Healthcard program a rather particular case of a targeted price subsidy scheme.

The particular design resulted in a weak link between Healthcard ownership and utilisation. We find that often Healthcard owners did not use their Healthcard when obtaining care from public service providers. Also we find many instances in which a patient reports the use of the Healthcard while the head of the household reports not to own a Healthcard. It seems like several factors are at play. High rejection rates could follow from the delays in the lump sum transfers made to the providers. The second case could arise if service providers distribute Healthcards when the patients show up to ask for services. The provider can offer subsidised services under the Healthcard program even though the patient did not show a Healthcard.

There is clear evidence that the 'pure' health care program was pro-poor in the sense that the poor had a higher probability of receiving a health card and if they received a health card, they increased the use of health services presumably making them healthier. Households in the poorest three quintiles increased overall outpatient utilisation. Females benefit more than males, possibly because of the maternity services covered under the Healthcard program. However, there is considerable leakage to the richer quintiles, and utilisation of services is less pro-poor than ownership. Conditional on ownership, the rich have a higher propensity to use their Healthcard.

Returning to the questions we started out with, we found that, for all households, ownership resulted in a large substitution effect away from the private sector to the public sector. The Healthcard program increased the quality of services provided at public providers and also induced those who received a Healthcard to use public providers at a subsidised rate. The results also show that the Healthcard program has had a positive direct effect on the overall use of outpatient medical services. 
A considerable proportion of the impact of the Healthcard program seems to have been through a general increase in the quality of public services. A dynamic analysis indicates that the Healthcard program resulted in an increase of the outpatient contact rate at public health care providers of 0.57 percentage point. In the event the Healthcard program would not have existed outpatient utilisation would have further fallen in 1999. However, the increased utilisation due to the direct Healthcard effect only contributes 0.19 percentage point to that. If this is true, the comeback of the public sector in the provision of outpatient care can be attributed for a large part to the quality increase induced by the Healthcard program.

Better targeting could have been achieved if there had been a closer link between reimbursements for public service providers and utilisation of the Healthcard. Those in the poorest quintile did only benefit from the Healthcard program if they received a Healthcard. If so, they increased their net utilisation of medical services. The result indicate that they did not benefit from the total quality increase, rather the opposite. The results suggest that while poor Healthcard owners increased their demand for public services, the poor that did not receive a health card reduced their demand for public services and increased demand for private sector services. Possibly the increased demand from the middle quintiles made public services less available for the poor that did not own a health card. While the targeting and impact of the pure health card program is pro-poor, the total effect is not. A stronger link between provision of services and budget would have increased the effect of the pure health relatively to the quality effect. 


\section{References:}

Ananta Aris and Reza Siregar (1999), "Social safety net policies in Indonesia:

Objectives and shortcomings”, ASEAN Economic Bulletin, Vol. 16, No. 3, pp. 344-359.

Dow, William H. (1999), "Flexible discrete choice demand models consistent with utility maximization: an application to health care demand”, American Journal of Agricultural Economics, Vol. 81, No. 3, pp. 680-85.

Gertler, Paul and J van der Gaag (1990), The willingness to pay for medical care : evidence from two developing countries, Baltimore : Published for the World Bank, Johns Hopkins University Press.

Jimenez, E. (1995) "Human and Physical Infrastructure: Public Investment and Pricing Policies in Developing Countries. ” Handbook of Development Economics, Vol. 3, J. Behrman and T.N. Srinivasan eds., chap. 43, pp. 2773843. Amsterdam: Elsevier, North Holland.

Lanjouw, Peter and Martin Ravallion (1995) "Poverty and Household Size”, Economic Journal, Vol. 105, No. 433, pp. 1415-1434.

Pradhan, Menno (2001) "Welfare analysis with a proxy consumption measure, Evidence from a repeated experiment in Indonesia”, working paper, Vrije Universiteit, Amsterdam.

Pradhan, Menno and Robert Sparrow (1999) “Indonesia Health Sector Analysis Changes in health indicators collected in the 1995, 1997, 1998 and 1999 SUSENAS household surveys”, working paper, Vrije Universiteit Amsterdam.

Rosenbaum, P and D. Rubin (1983), "The central role of the propensity score in observational studies for causal effects”, Biometrika, Vol. 70, pp 41-55.

Saadah, Fadia, Menno Pradhan and Soedarti Surbakti (2000) “ Health care during financial crisis: What can we learn from the Indonesian National socioeconomic Survey?”, Health, Nutrition and Population working paper, the World Bank, Washington DC.

Soelaksono, Bambang, Sri Budiyati, Hastuti, Musriyadi Nabiu, Akhmadi, Pamadi Wibowo, Sri Kusumastuti Rahaya and John Maxwell (1999), “The impact of the crisis on the people's behavior and perceptions of the use and effectiveness 
of Puskesmas, Posyandu, and the role of midwifes”, SMERU Special Report, Jakarta.

SSN Programs Management Coordinating Team (2000) “Indonesia’s Social Safety Net Programs - Fiscal year 1999/2000”, Brochure.

Suryahadi, Asep, Sudarno Sumarto, Yusuf Suharso and Lant Pritchett (1999) “The evolution of Poverty during the Crisis in Indonesia, 1996 to 1999” SMERU working paper, Jakarta. 
Tables and Figures

Table 1 Descriptive statistics for households with and without a Healthcard, and for the matched control group

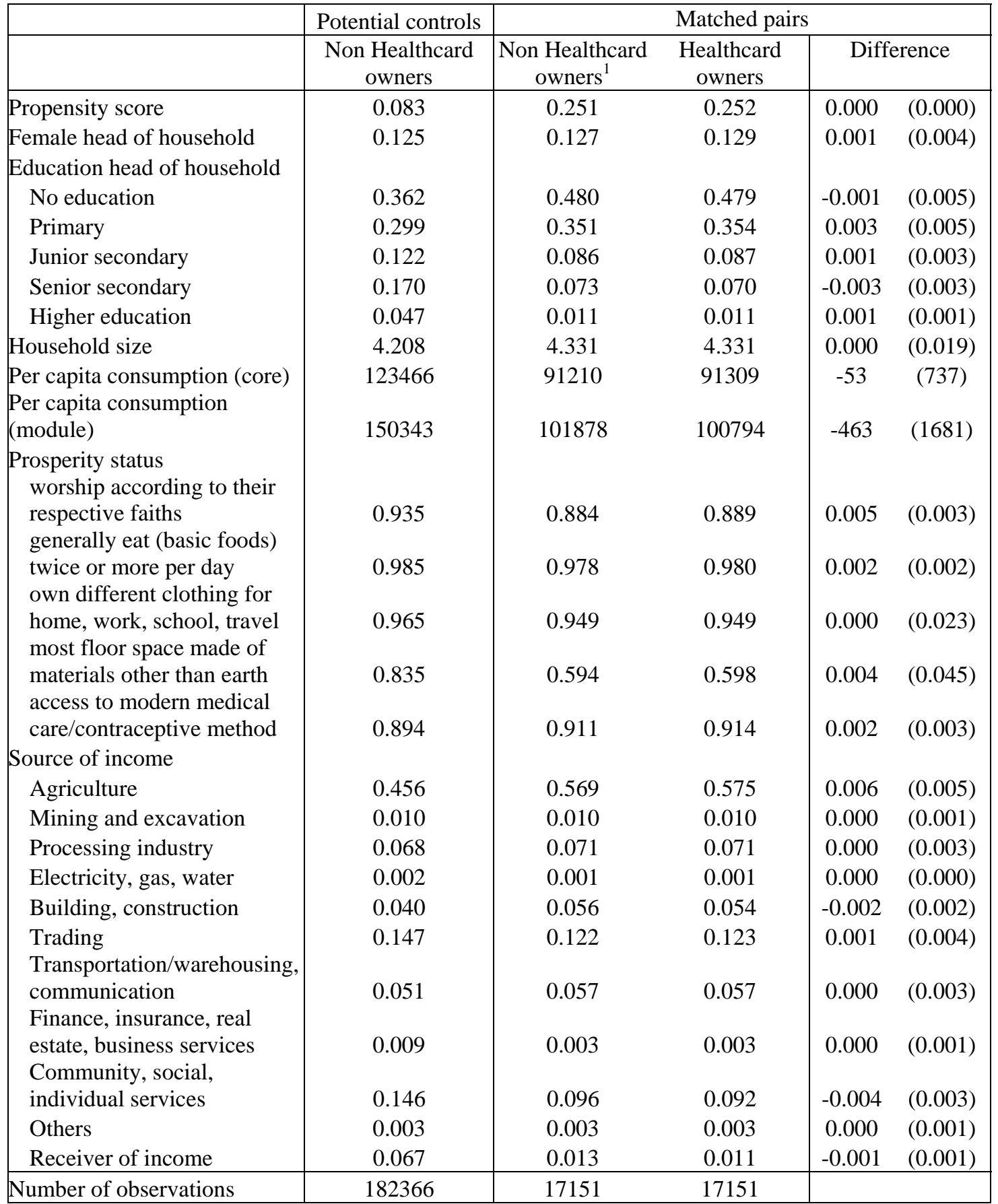

Note: standard errors in parentheses.

${ }^{1)}$ Includes 365 households that are matched more than once. 
Table 2 Utilisation of Healthcard (percent that sought care in past three months)

\begin{tabular}{|l|c|c|}
\hline & $\begin{array}{c}\text { Head of household reports to } \\
\text { have received a Healthcard }\end{array}$ & $\begin{array}{c}\text { Head of household reports } \\
\text { not to have received a } \\
\text { Healthcard }\end{array}$ \\
\hline Received outpatient care & 15.10 & 12.91 \\
\hline Went to public provider & 10.61 & 6.75 \\
\hline $\begin{array}{l}\text { Went to public provider and } \\
\text { used Healthcard }\end{array}$ & 6.74 & 0.15 \\
\hline $\begin{array}{l}\text { Went to public provider and } \\
\text { did not use Healthcard }\end{array}$ & 3.88 & 6.60 \\
\hline Went to private provider & 4.82 & 6.48 \\
\hline Did not seek health care & 84.57 & 86.77 \\
\hline
\end{tabular}

Table 3 Budget allocation to public health care providers, 1998/1999 from the Social Safety Net Program (Rupiah $x$ 1000)

\begin{tabular}{|l|r|r|r|r|}
\hline Region & $\begin{array}{c}\text { Total budget for } \\
\text { Puskesmas }\end{array}$ & Population size & \multicolumn{1}{c|}{$\begin{array}{c}\text { Budget per } \\
\text { capita }\end{array}$} & \multicolumn{1}{c|}{$\begin{array}{c}\text { Number of } \\
\text { districts }\end{array}$} \\
\hline Java Bali & $157,758,669$ & $122,095,101$ & 1.292 & 116 \\
\hline Sumatra & $54,097,540$ & $43,398,820$ & 1.247 & 73 \\
\hline Sulawesi & $25,009,892$ & $14,545,419$ & 1.719 & 40 \\
\hline Kalimantan & $15,747,384$ & $11,213,588$ & 1.404 & 29 \\
\hline Other islands & $36,431,997$ & $11,968,599$ & 3.044 & 35 \\
\hline Indonesia & $289,045,482$ & $203,221,527$ & 1.422 & 293 \\
\hline
\end{tabular}

Source: Ministry of Health and Social Welfare, Indonesia

Note: excluding East Timor.

1) Based on Susenas weights. 


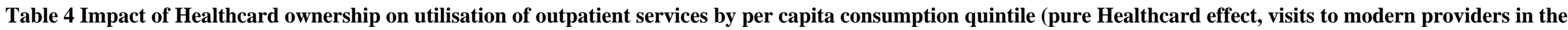
past 3 and 1 month, estimates are multiplied by 100 to give percentages)

\begin{tabular}{|c|c|c|c|c|c|c|c|c|c|c|c|}
\hline & \multicolumn{5}{|c|}{3 months reference period } & \multicolumn{5}{|c|}{1 month reference period } & \multirow{2}{*}{$\begin{array}{l}\text { Probability of } \\
\text { selection into } \\
\text { the program } \\
(\hat{p})\end{array}$} \\
\hline $\begin{array}{l}\text { All outpatient } \\
\text { visits }\end{array}$ & $\begin{array}{l}\text { Intervention } \\
\text { group }\end{array}$ & $\begin{array}{l}\text { Control } \\
\text { group }\end{array}$ & $\begin{array}{l}\text { Difference } \\
(\hat{\beta} * 100)\end{array}$ & t-value & $\begin{array}{l}\text { Direct effect } \\
(\hat{p} \hat{\beta} * 100)\end{array}$ & $\begin{array}{l}\text { Intervention } \\
\text { group }\end{array}$ & $\begin{array}{l}\text { Control } \\
\text { group }\end{array}$ & $\begin{array}{l}\text { Difference } \\
(\hat{\beta} * 100)\end{array}$ & t-value & $\begin{array}{l}\text { Direct effect } \\
(\hat{p} \hat{\beta} * 100)\end{array}$ & \\
\hline 1 (poor) & 12.58 & 11.14 & 1.44 & 4.92 & 0.27 & 9.77 & 8.49 & 1.28 & 4.91 & 0.24 & 0.189 \\
\hline 2 & 14.15 & 13.35 & 0.81 & 2.25 & 0.11 & 11.23 & 10.44 & 0.79 & 2.46 & 0.11 & 0.137 \\
\hline 3 & 16.53 & 15.05 & 1.49 & 3.47 & 0.16 & 13.85 & 12.04 & 1.81 & 4.59 & 0.19 & 0.105 \\
\hline 4 & 16.96 & 16.50 & 0.47 & 0.88 & 0.03 & 13.90 & 13.53 & 0.37 & 0.75 & 0.03 & 0.069 \\
\hline 5 (rich) & 17.42 & 16.67 & 0.75 & 0.95 & 0.03 & 15.20 & 14.39 & 0.81 & 1.09 & 0.03 & 0.034 \\
\hline Male & 13.75 & 13.12 & 0.63 & 2.49 & 0.07 & 11.25 & 10.60 & 0.65 & 2.82 & 0.07 & 0.105 \\
\hline Female & 15.48 & 14.02 & 1.46 & 5.54 & 0.16 & 12.35 & 10.89 & 1.46 & 6.15 & 0.16 & 0.108 \\
\hline All & 14.62 & 13.57 & 1.05 & 5.74 & 0.11 & 11.81 & 10.75 & 1.06 & 6.39 & 0.11 & 0.106 \\
\hline \multicolumn{12}{|c|}{ Outpatient public } \\
\hline 1 (poor) & 9.45 & 7.12 & 2.33 & 9.38 & 0.44 & 7.21 & 5.61 & 1.60 & 7.22 & 0.30 & 0.189 \\
\hline 2 & 9.82 & 7.71 & 2.11 & 7.19 & 0.29 & 7.42 & 5.81 & 1.62 & 6.27 & 0.22 & 0.137 \\
\hline 3 & 10.84 & 8.01 & 2.82 & 8.24 & 0.30 & 8.77 & 6.03 & 2.74 & 8.94 & 0.29 & 0.105 \\
\hline 4 & 10.57 & 8.43 & 2.13 & 5.10 & 0.15 & 8.59 & 7.03 & 1.56 & 4.07 & 0.11 & 0.069 \\
\hline 5 (rich) & 10.85 & 7.87 & 2.97 & 4.86 & 0.10 & 8.17 & 6.34 & 1.82 & 3.35 & 0.06 & 0.034 \\
\hline Male & 9.00 & 7.31 & 1.69 & 8.34 & 0.18 & 7.10 & 5.79 & 1.31 & 7.19 & 0.14 & 0.105 \\
\hline Female & 11.08 & 8.10 & 2.98 & 13.69 & 0.32 & 8.50 & 6.18 & 2.32 & 12.00 & 0.25 & 0.108 \\
\hline All & 10.05 & 7.70 & 2.35 & 15.73 & 0.25 & 7.81 & 5.99 & 1.82 & 13.69 & 0.19 & 0.106 \\
\hline \multicolumn{12}{|c|}{ Outpatient private } \\
\hline 1 (poor) & 3.13 & 4.02 & -0.89 & -5.29 & -0.17 & 2.96 & 3.26 & -0.30 & -1.91 & -0.06 & 0.189 \\
\hline 2 & 4.33 & 5.63 & -1.31 & -5.76 & -0.18 & 4.51 & 5.27 & -0.76 & -3.40 & -0.10 & 0.137 \\
\hline 3 & 5.70 & 7.03 & -1.33 & -4.64 & -0.14 & 5.91 & 6.62 & -0.71 & -2.49 & -0.07 & 0.105 \\
\hline 4 & 6.40 & 8.07 & -1.67 & -4.51 & -0.11 & 6.28 & 7.28 & -0.99 & -2.77 & -0.07 & 0.069 \\
\hline 5 (rich) & 6.57 & 8.79 & -2.23 & -4.01 & -0.08 & 8.44 & 8.90 & -0.46 & -0.79 & -0.02 & 0.034 \\
\hline Male & 4.75 & 5.81 & -1.06 & -6.38 & -0.11 & 4.80 & 5.37 & -0.56 & -3.45 & -0.06 & 0.105 \\
\hline Female & 4.40 & 5.92 & -1.53 & -9.30 & -0.16 & 4.59 & 5.30 & -0.71 & -4.42 & -0.08 & 0.108 \\
\hline All & 4.57 & 5.87 & -1.30 & -11.09 & -0.14 & 4.70 & 5.33 & -0.64 & -5.56 & -0.07 & 0.106 \\
\hline
\end{tabular}

Note: bold indicates significance at 5 percent level. 
Table 5 Effect of PSK budget allocation (overall effect on visits to modern providers in the past 1 month, estimate of $\gamma$ in equation (5), multiplied by 100 to give percentages)

\begin{tabular}{|c|c|c|c|c|c|c|c|c|c|}
\hline & \multicolumn{3}{|c|}{ All outpatient visits } & \multicolumn{3}{|c|}{ Outpatient public } & \multicolumn{3}{|c|}{ Outpatient private } \\
\hline Quintile & $\hat{\gamma} * 100$ & t-value & $\begin{array}{c}\text { Overall effect } \\
(\hat{\gamma} \overline{P S K} * 100)\end{array}$ & $\hat{\gamma}^{*} 100$ & t-value & $\begin{array}{c}\text { Overall effect } \\
(\hat{\gamma} \overline{P S K} * 100)\end{array}$ & $\hat{\gamma} * 100$ & t-value & $\begin{array}{l}\text { Overall effect } \\
(\hat{\gamma} \overline{P S K} * 100)\end{array}$ \\
\hline 1(poor) & 0.58 & 1.23 & 0.83 & 0.07 & 0.22 & 0.11 & 0.58 & 1.69 & 0.82 \\
\hline 2 & 0.74 & 2.03 & 1.05 & 0.70 & 2.50 & 0.99 & 0.16 & 0.84 & 0.22 \\
\hline 3 & 0.31 & 0.96 & 0.44 & 0.30 & 1.22 & 0.43 & 0.00 & 0.02 & 0.01 \\
\hline 4 & 0.70 & 1.97 & 0.99 & 0.64 & 2.44 & 0.91 & 0.15 & 0.66 & 0.21 \\
\hline 5 (rich) & 0.35 & 0.85 & 0.49 & 0.49 & 1.88 & 0.70 & -0.23 & -0.75 & -0.33 \\
\hline Male & 0.42 & 1.79 & 0.59 & 0.34 & 2.34 & 0.48 & 0.11 & 0.73 & 0.15 \\
\hline Female & 0.49 & 1.93 & 0.69 & 0.47 & 2.59 & 0.67 & 0.09 & 0.58 & 0.12 \\
\hline All & 0.45 & 1.96 & 0.64 & 0.40 & 2.61 & 0.57 & 0.10 & 0.69 & 0.14 \\
\hline
\end{tabular}

Note: bold indicates significance at 5 percent level.

Note: $\overline{P S K}=1.422$ (see Table 3 ) 


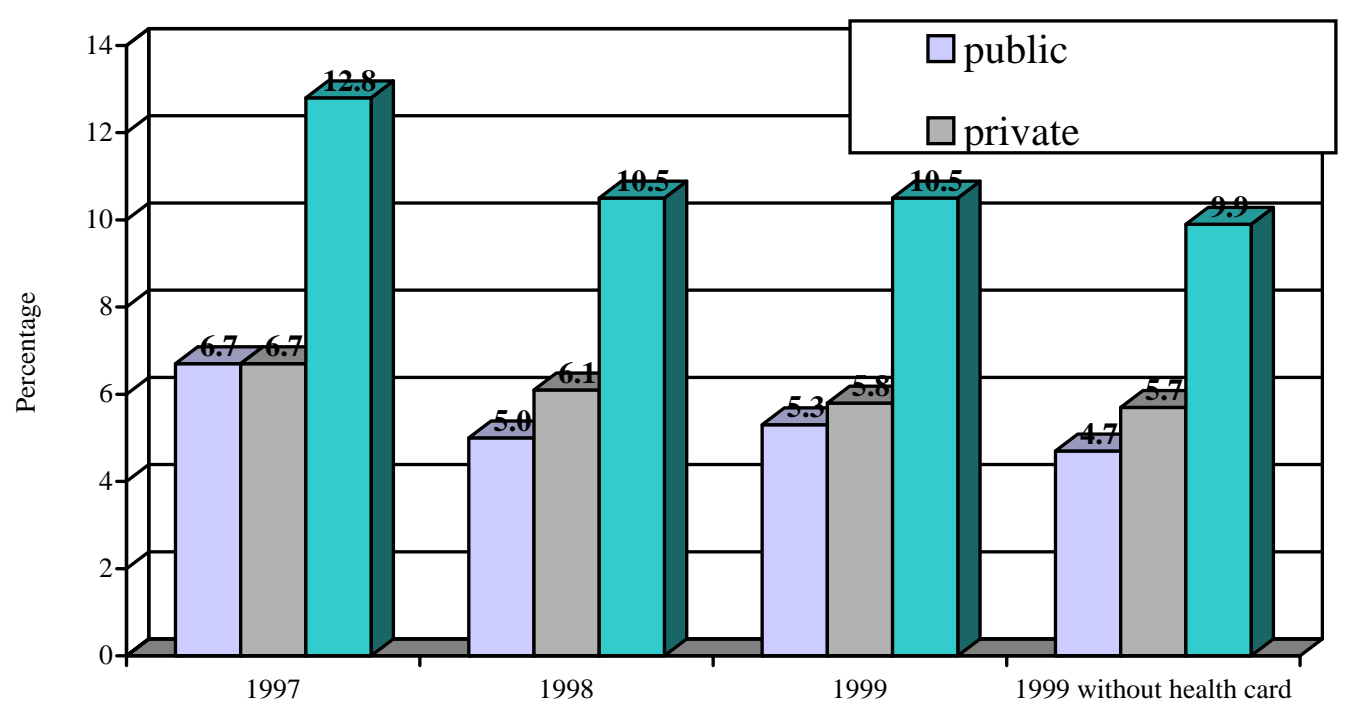

Figure 1 Portion people that consulted a health care provider at least once, on an outpatient basis, in 1997 to 1999, by type of provider (percent)

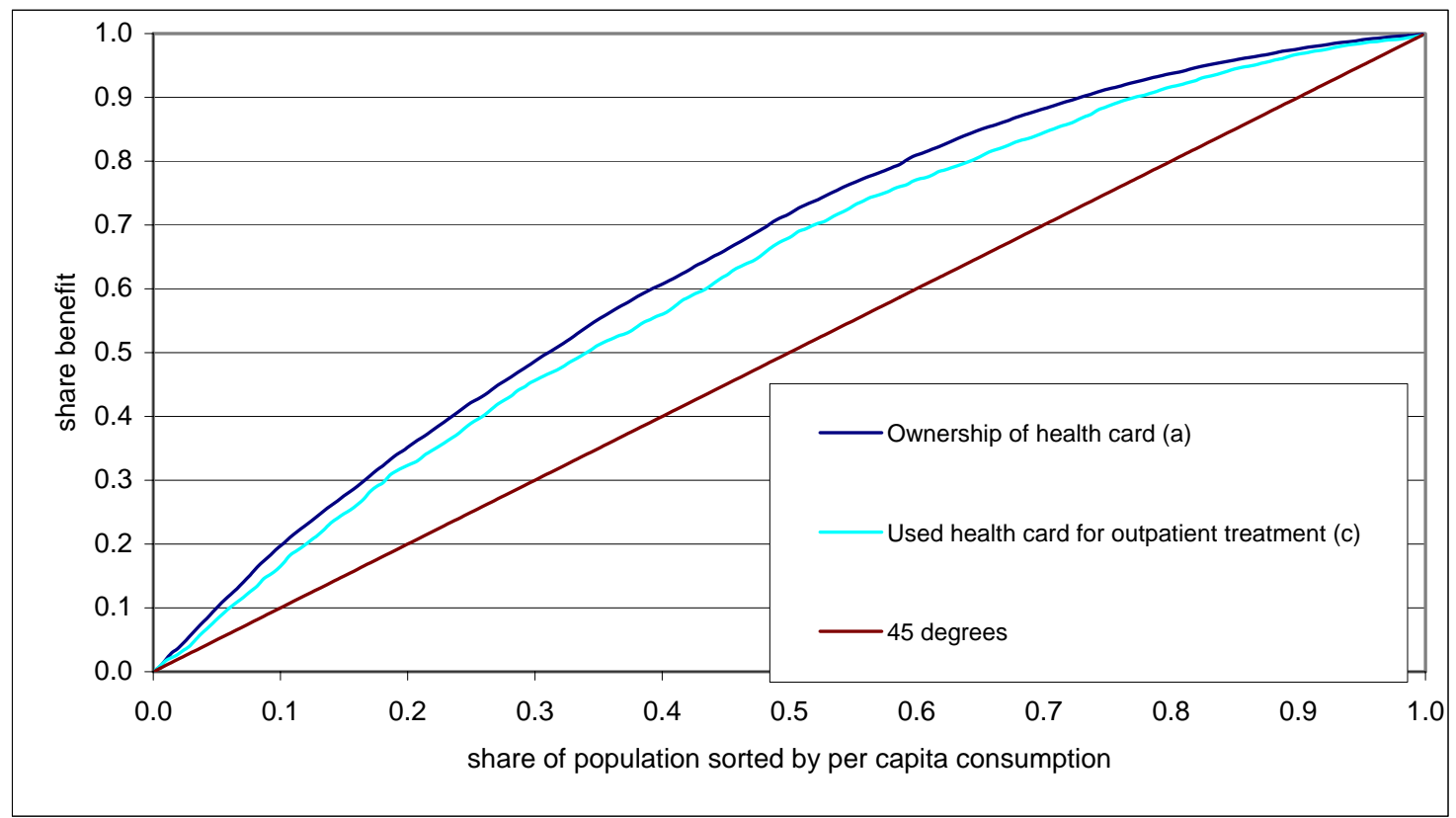

Figure 2 Concentration curve for ownership and use of Healthcard to obtain benefits associated with outpatient treatment 


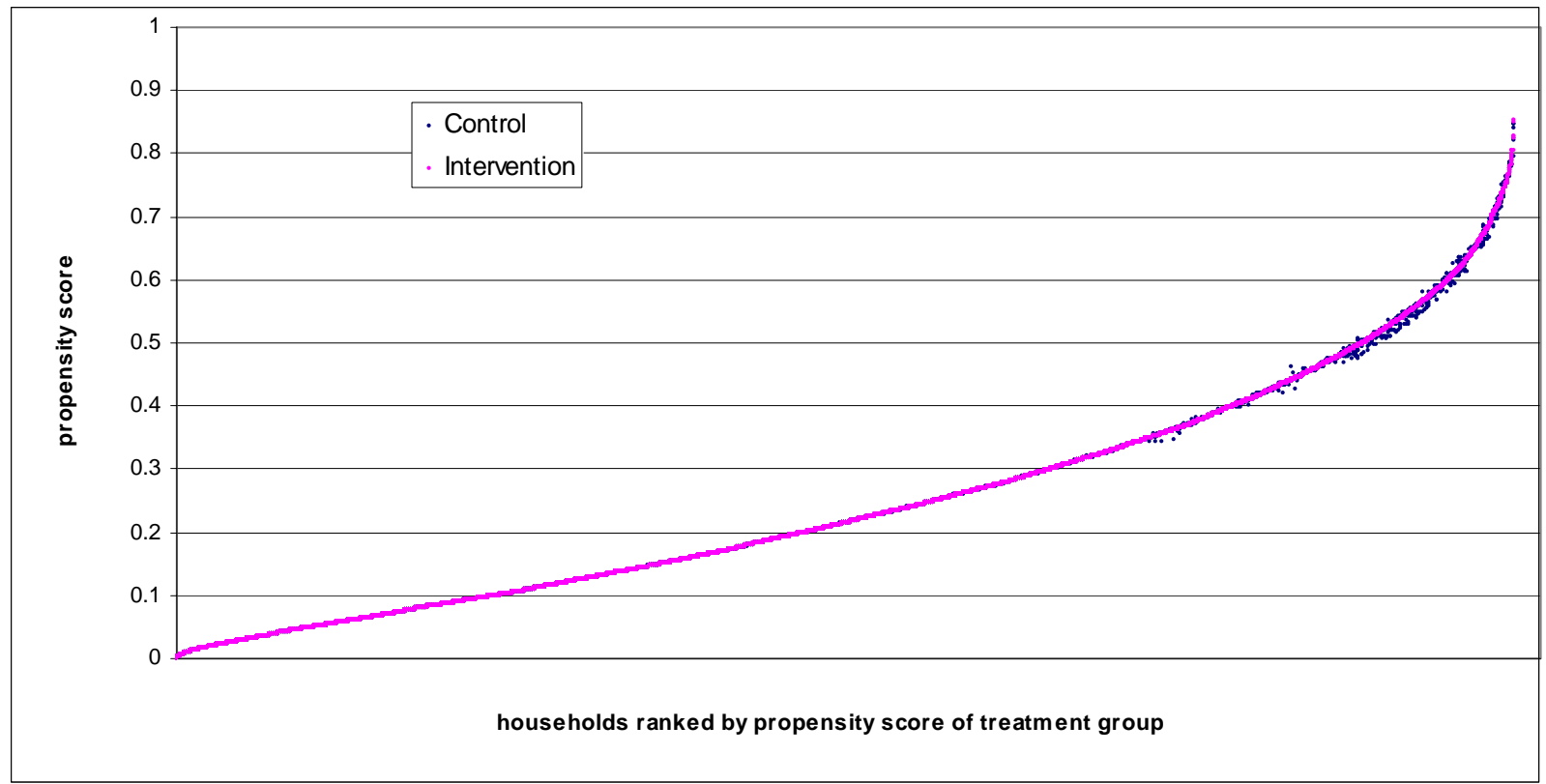

Figure 3 Propensity score match 